\title{
DESENVOLVIMENTO DE FRUTOS DE LONGAN (Dimocarpus longan Lour) NA REGIÃO DE JABOTICABAL-SP'
}

\author{
NATANAEL DE JESUS ${ }^{2}$, ANTONIO BALDO GERALDO MARTINS ${ }^{3}$, JOSÉ CARLOS BARBOSA ${ }^{4}$
}

RESUMO - O presente estudo teve por objetivo avaliar o desenvolvimento de frutos de plantas de longan (Dimocarpus longan Lour) na região de Jaboticabal, estabelecendo-se, portanto, a curva de crescimento dos frutos. As avaliações realizadas foram semanais, consistindo em medições do diâmetro longitudinal e transversal dos frutos marcados, a partir do momento da formação da polpa. Quinzenalmente, realizaram-se avaliações de características físicas: massa de fruto (g), casca (g), polpa (g) semente (g), e químicas: acidez titulável (AT), sólidos solúveis (SS), ácido ascórbico (AA) e ratio (SS/AT). Com os resultados obtidos, pode-se concluir que o ciclo de frutificação da Longan na região é entre 120 e 130 dias após antese, período em que o fruto estaria apto para o consumo. A curva do desenvolvimento dos frutos segue um padrão sigmoidal simples. Com relação aos atributos físicos e químicos, constatouse que a planta 6 apresentou os melhores resultados, podendo ser recomendada como planta-matriz.

Termos para indexação: Longana, biometria, Sapindaceae, olho-do-dragão.

\section{DEVELOPMENT OF LONGAN (Dimocarpus longan Lour) FRUITS IN THE REGION OF}

\section{JABOTICABAL-SP, BRAZIL}

ABSTRACT- This work was carried out to evaluate the development of longan (Dimocarpus longan Lour) fruits in the region of Jaboticabal, and establish the fruit growth curve. Weekly evaluations were performed to measure longitudinal and transversal diameter of selected fruits after pulp formation. Every two weeks, physical and chemical parameters were evaluated: fruit, peel, pulp and seed mass (g); titrable acidity (TA), soluble solids (SS), ascorbic acid (AA) and the ratio (SS/TA). Results indicate that longan reproductive cycle in the region is 120 to 130 days after anthesis, period after which the fruit is good for consumption, when the fruit development curve follows a simple sigmoidal pattern. Physical and chemical parameters have shown that the longan fruits analyzed here have a high consumption potential.

Index terms: Biometry, Longana, Sapindaceae, eyes- dragon.

\section{INTRODUÇÃO}

A procura pela diversificação de culturas proporcionou aumento pelo interesse de cultivo de frutíferas exóticas. O Brasil possui grande potencial para diversas espécies, pois apresenta uma diversidade muito grande de tipos de solos e climas que favorecem o plantio de frutíferas tropicais, subtropicais e temperadas (SIMÃO, 1998).

Em 2005, foram comercializadas cerca 1,52 milhão de toneladas de frutas no CEAGESP. As frutas exóticas com 1.184,94 toneladas representaram cerca de $0,08 \%$ desse volume, sendo que as frutas da família Sapindaceae representaram 31,9\% desse total, com destaque para a lichia, fruta com maior volume dentre as exóticas (GODAS et al., 2006).

A longan (Dimocarpus longan Lour), também conhecida como longana e "olho-do- dragão", é originária do Sul da Ásia, mais especificamente da China, pertencente à família Sapindaceae, mesma da Lichia (Litchi chinenses Sonn). Apesar de pouco conhecida, está distribuída em todas as regiões subtropicais do mundo, sendo uma grande opção de plantio, afinal a árvore é mais rústica que a da lichia, adaptando-se a uma maior amplitude de clima (FERRÃO, 1999). No Brasil, são poucos os trabalhos e as informações sobre a cultura.

A planta dificilmente excede os $20 \mathrm{~m}$ de altura, possui uma copa variando entre redonda e ereta, e seu tronco é rugoso. As folhas são pecioladas e alternas, apresentando um número variável de folíolos dispostos na ráquis de forma alternada (GALAN-SAUCO, 1990). O fruto é uma drupa esférica com 2 a 3 cm de diâmetro; quando maduro, possui coloração castanha e de sabor menos pronunciado que a lichia, mas bastante agradável, e a polpa é translúcida e adocicada, com uma semente de cor escura e brilhante. O consumo é como fruta fresca ou seca (FERRÃO, 1999; BENZA, 1993).

O conhecimento do padrão de crescimento dos frutos durante o desenvolvimento é necessário para definir técnicas de colheita, manuseio e conservação pós-colheita, assim como para definir índices de maturação e qualidade (ARAÚJO NETO et al., 2001; CARNEIRO, 1986a).

Além dos fatores já citados, o conhecimento das

\footnotetext{
(Trabalho 106-07). Recebido em: 19-04-2007. Aceito para publicação em: 14-12-2007.

${ }^{2}$ Eng. Agr., M.Sc., Doutorando em Agronomia, Área de Concentração em Produção Vegetal. FCAV/UNESP - Via de Acesso Prof. Paulo Donato Castellane s/n, CEP 14884-900. Jaboticabal-SP. E-mail: natanael@fcav.unesp.br.

${ }^{3}$ Eng. Agr., Dr., Professor Assistente Doutor do Departamento de Produção Vegetal da FCAV/UNESP, Câmpus de Jaboticabal-SP. E-mail: baldo@fcav.unesp.br ${ }^{4}$ Eng. Agr., Dr., Professor Titular Doutor do Departamento de Ciências Exatas Vegetal da FCAV/UNESP, Câmpus de Jaboticabal-SP. Email:jcbarbosa@fcav.unesp.br.
} 
características físicas, químicas e morfológicas dos frutos pode contribuir para seleção de cultivares promissoras, cujos frutos, além de serem utilizados ao natural, sejam destinados também para a industrialização (CARNEIRO, 1986b).

CHITARRA \& CHITARRA (1990) mencionam que o desenvolvimento do fruto ocorre segundo uma curva sigmoidal simples ou dupla; já WACHOAWICZ \& CARVALHO (2002) relatam que este crescimento ocorre em três fases. A primeira é caracterizada por intensa divisão celular, elevada pela atividade metabólica; a segunda fase é caracterizada pelo aumento do tamanho das células e diminuição da intensidade respiratória; a terceira fase corresponde à maturação que se caracteriza pela baixa atividade respiratória.

Os processos de deterioração ocorridos no amadurecimento relacionam-se, de modo geral, com a degradação dos carboidratos de reserva, com a redução nos conteúdos de ácidos orgânicos e polifenóis, e com as mudanças na pigmentação (LIMA, 2003).

Sendo assim, as características químicas indicam com maior precisão o estádio de maturação, porque as características físicas podem conduzir a conclusões equivocadas, uma vez que o manejo das plantas, durante o ciclo produtivo, pode ser distinto. Os atributos químicos mais utilizados são conteúdo de sólidos solúveis, acidez titulável, relação açúcares/acidez e àcido ascórbico. Todos são comparados com curvas-padrão, preestabelecidas para cada espécie. Com o amadurecimento, há uma alteração nesses fatores que indica o nível de maturação dos frutos (WACHOWICZ \& CARVALHO, 2002).

O conhecimento das fases do desenvolvimento dos frutos é essencial para auxiliar na determinação de práticas culturais, principalmente quanto ao estádio de maturação adequado para a colheita comercial (GRIERSON, 1995). Desse modo, o objetivo do presente trabalho foi estudar o desenvolvimento do fruto de longan (Dimocarpus longan) na região de Jaboticabal-SP.

\section{MATERIAL E MÉTODOS}

As avaliações foram realizadas em seis plantas de Longan, oriundas de sementes, introduzidas em 1986 como mudas de pé-franco, pela Unesp de Jaboticabal, provenientes da Flórida, mas desenvolvidas no Havaí, de livre crescimento, conduzidas sem irrigação ou adubação, com espaçamento de $4 \mathrm{x}$ $5 \mathrm{~m}$, pertencentes à coleção da Faculdade de Ciências Agrárias e Veterinárias (FCAV/UNESP), Câmpus de Jaboticabal-SP, no período de outubro de 2004 a fevereiro de 2005 . As coordenadas geográficas do local são $21^{\circ} 17^{\prime} 05^{\prime \prime}$ latitude sul; 48 $17^{\prime} 09^{\prime \prime}$ longitude oeste, com altitude de aproximadamente $590 \mathrm{~m}$. O clima da região, segundo classificação de Köeppen é do tipo Cwa, subtropical, com inverno moderado e seco, verão quente e chuvoso, apresentando temperatura média anual de $22^{\circ} \mathrm{C}$ e precipitação pluviométrica média de $1.552 \mathrm{~mm}$.

As avaliações biométricas dos frutos de longan iniciaram 35 dias após a antese (daa) e terminaram aos 140 dias após a antese. As panículas, 25 por planta, foram marcadas com uma fita plástica preta de $1,0 \mathrm{~m}$ de comprimento e não tiveram seus frutos colhidos ao longo do trabalho. Essas panículas foram numeradas e tiveram cinco frutos mensurados quanto aos diâmetros longitudinal e transversal.

As avaliações físicas e químicas foram realizadas quinzenalmente, coletando-se 100 frutos por planta das regiões apical, mediana e basal da panícula, objetivando maior uniformidade da amostra, sendo coletados frutos de panículas que não estavam marcadas. O objetivo foi avaliar o grau de desenvolvimento dos frutos e verificar se ocorria diferença significativa entre o crescimento dos frutos analisados.

Os frutos coletados, a cada época, foram transportados ao Laboratório de Produtos Hortícolas do Departamento de Produção Vegetal da UNESP-FCAV, para as seguintes avaliações: diâmetro transversal $(\mathrm{cm})$, longitudinal $(\mathrm{cm})$, massa de fruto $(\mathrm{g})$, casca $(\mathrm{g})$, polpa $(\mathrm{g})$ e semente $(\mathrm{g})$. Quanto às características químicas, analisaram-se: acidez titulável (AT), sólidos solúveis (SS), ambos segundo metodologia descrita por A.O.A.C. (1997 método 942-15 e 932-12, respectivamente), ácido ascórbico (AA) titulado com reagente de Tillman (2,6 diclorofenlindofenol de sódio a 0,1\%), segundo STROHECKER \& HENNING, 1967, e ratio $(\mathrm{SS} / \mathrm{AT})$.

As características físicas dos frutos foram analisadas pelo programa SAS, e as médias, comparadas pelo teste de Tukey, a $5 \%$ de probabilidade. Para a confecção das figuras, os dados analisados referentes ao diâmetro longitudinal e transversal foram ajustados, utilizando-se do programa gráfico 'Origin 6.0' através da composição de uma função logística, com uma exponencial quadrática, onde: $\mathrm{Y}=\mathrm{A} /\left[1+\mathrm{e}^{-\mathrm{k}(\mathrm{x}-\mathrm{xc})}\right]+\left[\mathrm{e}^{\left(\mathrm{a}+b \mathrm{bx}+\mathrm{cx} \mathrm{x}^{2}\right)}\right]$, sendo: $\mathrm{Y}=$ valor médio da característica avaliada; $\mathrm{A}=$ máximo assintótico (crescimento máximo); $\mathrm{e}=$ base do logaritmo neperiano; $\mathrm{k}=$ taxa média de crescimento; $\mathrm{x}=$ tempo (em dias), e $\mathrm{xc}=$ tempo em que a variável $\mathrm{Y}$ atinge metade do crescimento máximo. Para as características químicas, realizou-se análise de variância, sendo as médias comparadas pelo teste de Tukey, a $5 \%$ de probabilidade.

\section{RESULTADOS E DISCUSSÃO}

Os valores referentes aos diâmetros longitudinal e transversal estão apresentados na Figura 1, e os valores de massa da matéria fresca (g), na Figura 2. Observa-se que, em todas as plantas avaliadas, o crescimento dos frutos segue um padrão sigmoidal, e que a planta 06 apresentou um crescimento mais acelerado, quando comparada às demais, atingido, portanto, a maturação mais precocemente, com um ciclo antecipado de duas semanas; as demais plantas avaliadas apresentam um resultado semelhante até os 130 após a antese (daa); contudo, depois desse período, quanto aos diâmetros dos frutos, não houve crescimento significativo em nenhuma delas, ocorrendo uma pequena queda na planta 1 , na última avaliação.

Analisando o diâmetro longitudinal, as plantas $1 ; 5$ e 6 tiveram crescimento semelhante, uma ressalva apenas para planta 1, que, no final do ciclo, apresentou pequena redução. $\mathrm{O}$ desenvolvimento para essas plantas foi acelerado, porque até o 77 daa observaram-se resultados semelhantes; entretanto, quando os frutos passaram este período até atingir os 130 daa, o crescimento foi intenso, chegando a dobrar o tamanho. Com 
relação ao diâmetro transversal, observou-se o mesmo comportamento, contudo o crescimento foi maior no sentido longitudinal (Figura 1).

O padrão de desenvolvimento dos frutos, de todas as plantas de longan avaliadas, é semelhante a uma sigmoidal simples, com duas fases distintas: na primeira ocorre um crescimento mais acentuado da casca e da semente; em seguida, quando os frutos estão com aproximadamente 116 dias após antese, há um crescimento mais acentuado da polpa (Figuras $1 \mathrm{e}$ 2).

Esse padrão concorda com o encontrado por SALOMÃO et al. (2006), que trabalharam com a cultivar 'Bengal' de lichia (Litchi chinensis Sonn.) e observaram que da fase inicial até 63 dias após a antese, o crescimento é lento; de 63 até 98 dias após a antese, há uma fase de acúmulo elevado de matéria seca, e, em seguida, ocorre uma estabilização com sensível queda no final, resultados semelhantes aos observados por NACIF (1997).

Embora haja algumas diferenças no padrão de desenvolvimento entre a lichia e a longan, WAITE \& HAVANG (2002) relataram que, nas plantas de longan, a abertura das flores ocorre de 2 a 3 semanas mais tarde que na lichieira, e a maturação é de 4 a 8 semanas mais tardia. Esses resultados são confirmados por GARCIA-PÉREZ \& MARTINS (2006), que trabalharam com anelamento e florescimento na lichieira. Observaram esse comportamento, além de conseguirem uma antecipação de 3 semanas na produção (início de dezembro). Esse aspecto é importante, pois a longan atinge seu ponto de colheita fora do período de comercialização da lichia, com a possibilidade de se tornar uma opção interessante de comercialização.

A planta 6 apresentou o melhor rendimento em polpa, com índices de 70,5\% na última avaliação, o que se deve ao fato de a semente ser menor, com valores que não ultrapassam os $8,0 \%$ do total do fruto; isto equivale dizer que, para essa planta, a massa fresca da casca teve participação mais acentuada quando comparada ao da própria semente (Figura 2). Estes resultados são superiores aos encontrados por LIMA et al. (2005), que analisaram frutos de longan na região de Botucatu e encontraram rendimento de $52,5 \%$.

Os valores médios de sólidos solúveis são apresentados na Tabela 1 , embora todas as plantas tenham apresentado valores satisfatórios no final do ciclo; a planta 6 , com 19,2 ${ }^{\circ}$ Brix, mais uma vez confirmou sua precocidade, apresentando já na terceira avaliação teores aceitáveis de SS para o consumo, enquanto as demais necessitaram de mais 7 a 10 dias, como a planta 1 , que foi mais tardia, apresentando o menor resultado. Os valores encontrados para as plantas 5 e 6 estão próximos aos citados pela literatura em seu país de origem, pois HAN et al. (2001), na China, citam valores de $21^{\circ}$ Brix, CAMPBELL \& CAMPBELL (2001) mencionam que, na Flórida, a variedade Kohala atingiu teores que variam de 17 a $21^{\circ}$ Brix. Por essa razão, podem-se considerar esses índices promissores.

Para acidez, os frutos das plantas $1 ; 2 ; 3 ; 4$ e 5 apresentaram teores significativamente mais elevados quando comparados com a planta 6 , que apresentou um resultado abaixo de $0,07 \%$ ác. cítrico, valores semelhantes aos mencionados por HAN et al. (2001), que citam teores próximos a 0,04 \%. Já LIMA et al. (2005) encontraram valores com $0,18 \%$, superiores aos da planta 6 , contudo são inferiores aos das demais plantas aqui estudadas (Tabela 1).

Para os valores de AA (ácido ascórbico), a planta 6 apresentou o melhor resultado, com teores de $157,64 \mathrm{mg} / 100 \mathrm{~g} \mathrm{de}$ polpa, próximo ao citado por LIMA et al. (2005), que mencionam $175,09 \mathrm{mg} / 100 \mathrm{~g}$ de polpa, e embora a planta 6 tenha-se destacado nestes valores, as demais plantas apresentaram valores aceitáveis de ácido ascórbico. Observaram-se três fatores: a planta 1 apresentou evolução lenta no acúmulo de AA ao longo das avaliações, chegando ao patamar de $78,25 \mathrm{mg} / 100 \mathrm{~g}$ no final, enquanto as plantas $2 ; 3$ e 5 tiveram redução na última avaliação, porque apresentavam sinais de senescência, enquanto na planta 06 havia ocorrido a abscisão dos frutos e, na planta 4 , um pequeno aumento (Tabela 2).

TABELA 1 - Valores médios de sólidos solúveis (SS) e Acidez titulável (AT) de frutos de longan (Dimocarpus longan), em função de dias após antese. Jaboticabal-SP, 2005.

\begin{tabular}{|c|c|c|c|c|c|c|c|c|}
\hline \multirow{3}{*}{ Planta } & \multicolumn{4}{|c|}{$\mathrm{SS}\left({ }^{\circ} \mathrm{Brix}\right)$} & \multicolumn{4}{|c|}{ AT (\% Ac. Cítrico) } \\
\hline & 102 & 116 & 130 & 144 & 102 & 116 & 130 & 144 \\
\hline & \multicolumn{4}{|c|}{ Dias Após Antese } & \multicolumn{4}{|c|}{ Dias Após Antese } \\
\hline 01 & $8,86 \mathrm{~b}$ & $5,90 \mathrm{~d}$ & $8,66 \mathrm{f}$ & $17,30 \mathrm{c}$ & $0,116 \mathrm{a}$ & 0,126 a & $0,146 \mathrm{ab}$ & $0,566 \mathrm{bc}$ \\
\hline 02 & $6,70 \mathrm{c}$ & $7,06 \mathrm{~b}$ & $14,22 \mathrm{c}$ & $18,31 \mathrm{~b}$ & $0,096 \mathrm{ab}$ & $0,105 \mathrm{ab}$ & $0,116 \mathrm{bc}$ & $0,526 \mathrm{c}$ \\
\hline 03 & $7,40 \mathrm{c}$ & $6,16 \mathrm{~cd}$ & $12,21 \mathrm{~d}$ & $17,92 \mathrm{bc}$ & $0,092 \mathrm{ab}$ & $0,105 \mathrm{ab}$ & $0,173 \mathrm{a}$ & $0,776 \mathrm{a}$ \\
\hline 04 & $7,00 \mathrm{c}$ & $6,56 \mathrm{bc}$ & $11,21 \mathrm{e}$ & $17,91 \mathrm{bc}$ & $0,081 \mathrm{ab}$ & $0,099 \mathrm{~b}$ & $0,100 \mathrm{~cd}$ & $0,696 \mathrm{ab}$ \\
\hline 05 & $6,53 \mathrm{c}$ & $6,86 \mathrm{bc}$ & $16,00 b$ & $20,51 \mathrm{a}$ & $0,071 \mathrm{~b}$ & $0,096 \mathrm{~b}$ & $0,110 \mathrm{~cd}$ & $0,420 \mathrm{c}$ \\
\hline 06 & $12,50 \mathrm{a}$ & $16,71 \mathrm{a}$ & $19,20 \mathrm{a}$ & $1--$ & $0,044 \mathrm{c}$ & $0,058 \mathrm{c}$ & $0,070 \mathrm{c}$ & $1--$ \\
\hline $\mathrm{F}$ & $87,05 * *$ & $15,73 * *$ & $312,48 * *$ & $49,74 * *$ & $13,74 * *$ & $15,73 * *$ & $21,67 * *$ & $19,81 * *$ \\
\hline DMS & 1,16 & 0,79 & 1,00 & 0.82 & 0,394 & 0,268 & 0,369 & 0,147 \\
\hline $\mathrm{CV}(\%)$ & 5,19 & 9,91 & 2,68 & 1,66 & 17,88 & 9,91 & 11,25 & 9,18 \\
\hline
\end{tabular}

Médias seguidas por letras distintas, na mesma coluna, diferem entre si, pelo teste de Tukey. ${ }^{* *}$ significativo ao nível de $1 \%$ de probabilidade. ${ }^{1}$ A planta 6, na última avaliação, não apresentou frutos. 
TABELA 2 - Valores médios de Ácido ascórbico (AA) e Ratio (SS/AT) de frutos de longan (Dimocarpus longan), em função de dias após antese. Jaboticabal-SP, 2005.

\begin{tabular}{|c|c|c|c|c|c|c|c|c|}
\hline \multirow{3}{*}{ Planta } & \multicolumn{4}{|c|}{$\mathrm{AA}(\mathrm{mg} / 100 \mathrm{~g})$} & \multicolumn{4}{|c|}{ SS/AT } \\
\hline & 102 & 116 & 130 & 144 & 102 & 116 & 130 & 144 \\
\hline & \multicolumn{4}{|c|}{ Dias Após Antese } & \multicolumn{4}{|c|}{ Dias Após Antese } \\
\hline 01 & $1,55 \mathrm{~d}$ & $9,01 \mathrm{~d}$ & $22,03 \mathrm{e}$ & $78,25 \mathrm{ab}$ & $76,4 \mathrm{~b}$ & $46,7 \mathrm{~b}$ & $59,4 \mathrm{~d}$ & $31,2 \mathrm{bc}$ \\
\hline 02 & $1,25 \mathrm{~d}$ & $6,80 \mathrm{~d}$ & $60,65 \mathrm{~d}$ & $33,13 \mathrm{c}$ & $70,3 \mathrm{~b}$ & $67,3 \mathrm{~b}$ & $123,2 \mathrm{~b}$ & $34,6 \mathrm{~b}$ \\
\hline 03 & $3,96 \mathrm{c}$ & $28,06 \mathrm{bc}$ & $64,94 \mathrm{~d}$ & $25,90 \mathrm{c}$ & $79,8 \mathrm{~b}$ & $58,8 \mathrm{~b}$ & $71,5 \mathrm{~cd}$ & $23,1 \mathrm{c}$ \\
\hline 04 & $2,47 \mathrm{c}$ & $15,58 \mathrm{~cd}$ & $84,54 \mathrm{c}$ & $86,56 \mathrm{a}$ & $85,7 \mathrm{~b}$ & $67,2 \mathrm{~b}$ & $112,0 \mathrm{bc}$ & $25,8 \mathrm{bc}$ \\
\hline 05 & $7,73 \mathrm{~b}$ & $35,86 \mathrm{~b}$ & $115,42 \mathrm{~b}$ & $68,96 \mathrm{~b}$ & $91,9 \mathrm{~b}$ & $69,7 \mathrm{~b}$ & $145,3 \mathrm{~b}$ & $48,9 \mathrm{a}$ \\
\hline 06 & $78,30 \mathrm{a}$ & $131,60 \mathrm{a}$ & 157,64 a & 1-- & $285,1 \mathrm{a}$ & 293,6 a & $275,3 \mathrm{a}$ & 1-- \\
\hline $\mathrm{F}$ & $68,05^{* *}$ & $255,57^{* *}$ & $262,64 * *$ & $84,83^{* *}$ & $19,8^{* *}$ & $47,75^{* *}$ & $262,64 * *$ & $26,94 * *$ \\
\hline DMS & 1,76 & 14,06 & 13,84 & 13,81 & 91,31 & 65,24 & 40,62 & 9,08 \\
\hline $\mathrm{CV}(\%)$ & 4,04 & 13,54 & 6,00 & 8,79 & 28,53 & 23,61 & 6,00 & 4,04 \\
\hline
\end{tabular}

Médias seguidas por letras distintas, na mesma coluna, diferem entre si, pelo teste de Tukey. ** significativo ao nível de $1 \%$ de probabilidade. ${ }^{1} \mathrm{~A}$ planta 6 , na última avaliação, não apresentou frutos.
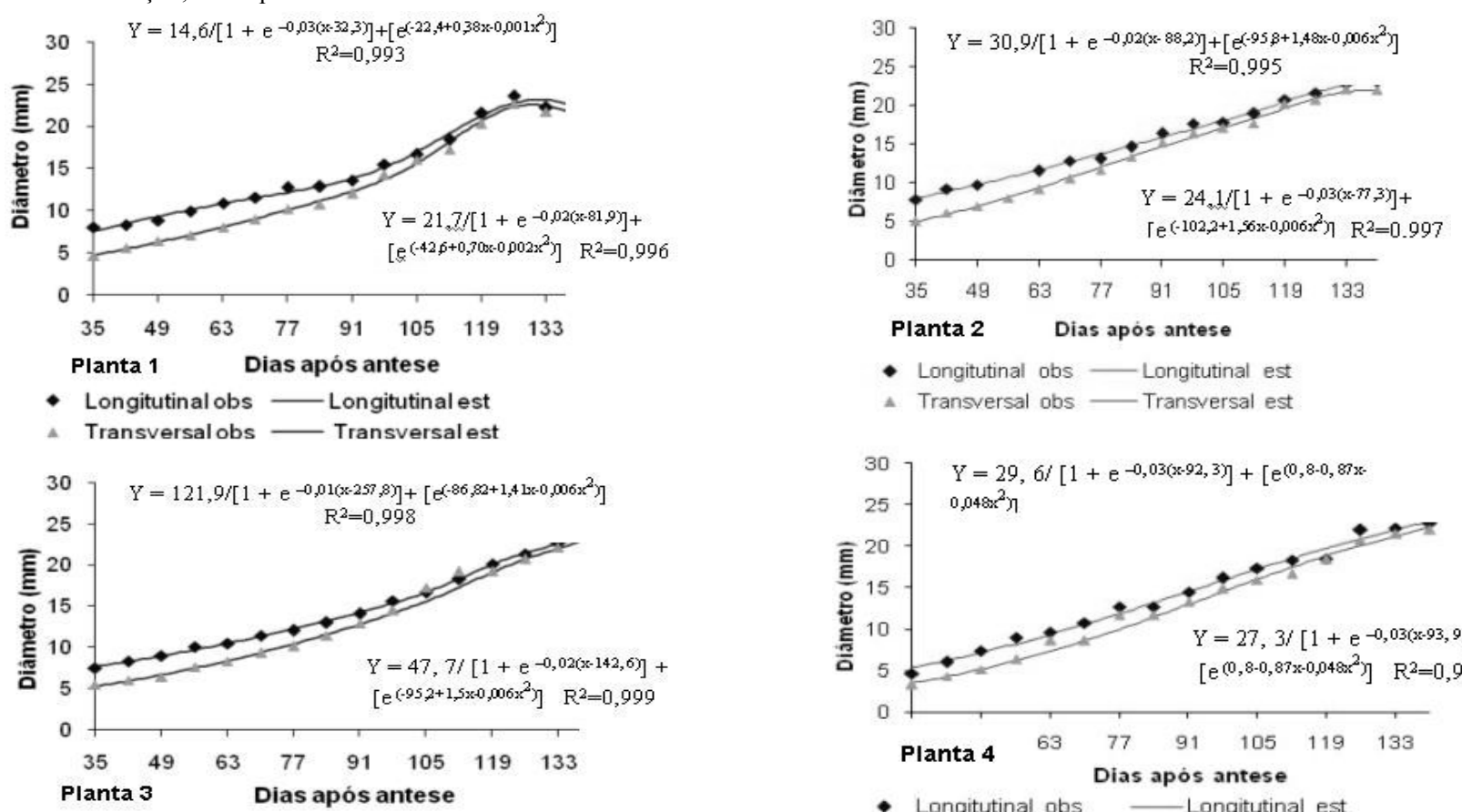

Planta 2 Dias apos antese

- Longitutinal obs — Longitutinal est

- Transversal obs - Transversal est

- Longitutinal obs Longitutinal est

4 Transversalobs - Transversalest
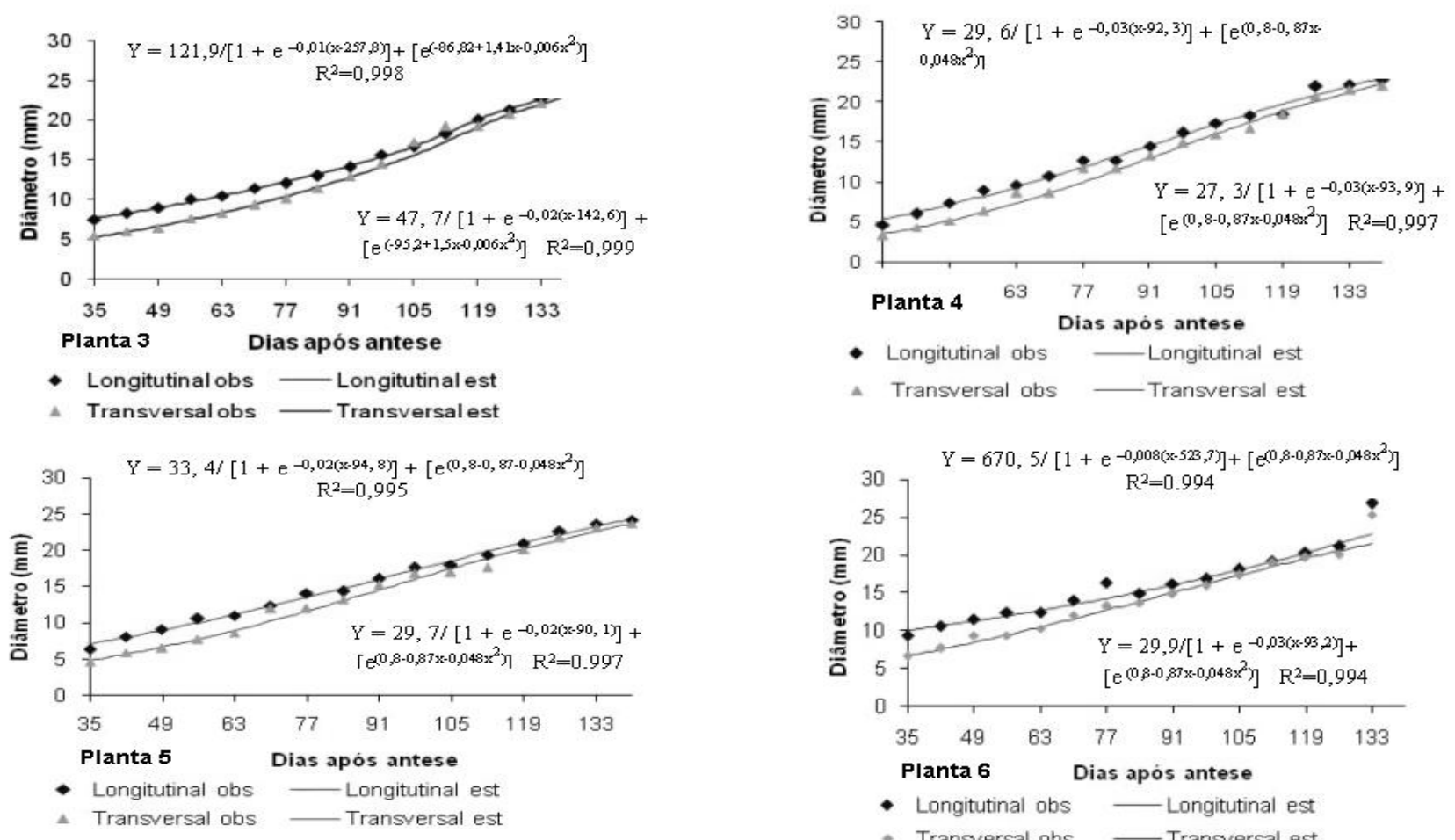

- Longitutinal obs Longitutinal est

4. Transversal obs - Transversal est

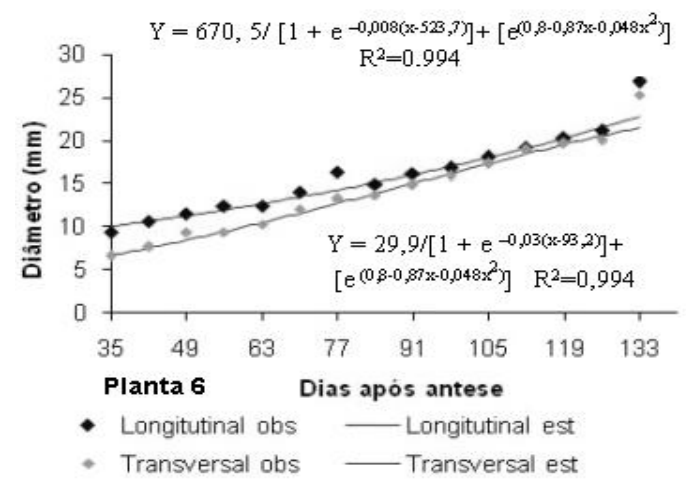

FIGURA 1- Diâmetro transversal e longitudinal (mm) de frutos de longan (Dimocarpus Longan), em função de dias após a antese. Jaboticabal-SP, Fevereiro de 2005. 

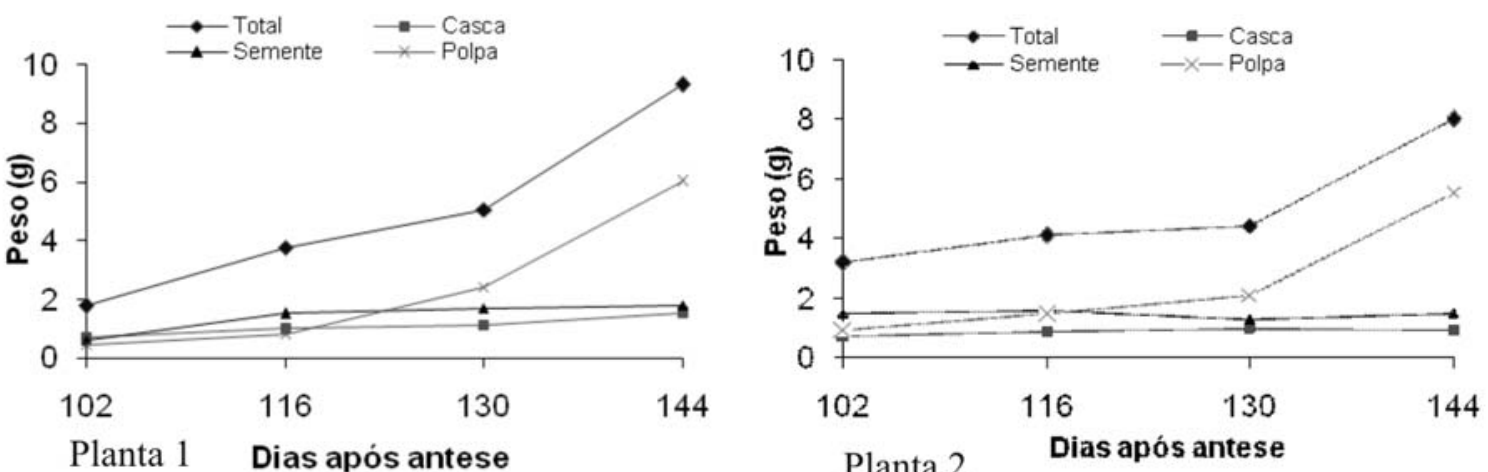

Planta 1 Dias após antese

Planta 2 Dias após antese

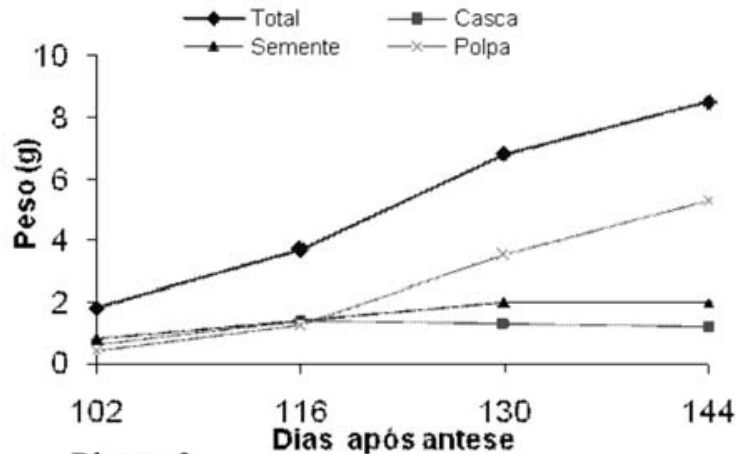

Planta 3

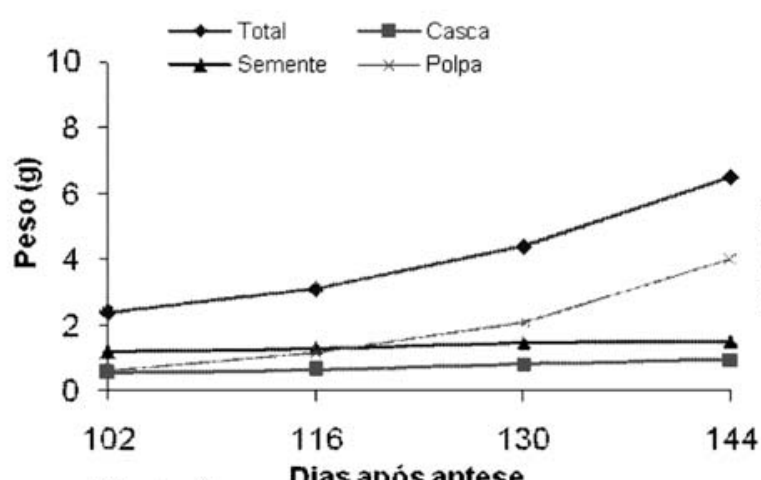

Planta 5

Dias após antese

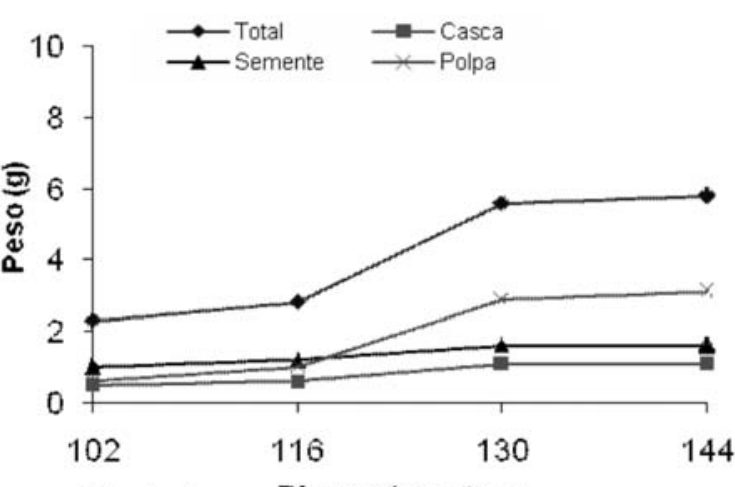

Planta 4 Dias após antese

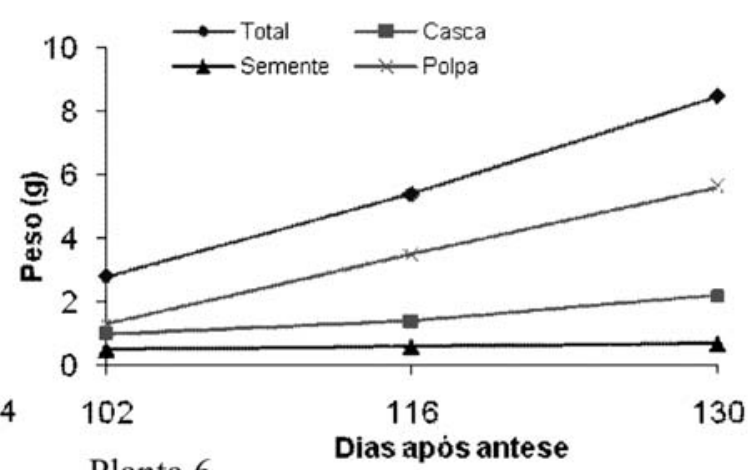

FIGURA 2 - Massa fresca (g): total, casca, polpa e semente de frutos de longan (Dimocarpus longan), em função dos dias após a antese. Jaboticabal-SP, 2005.

\section{CONSIDERAÇÕES GERAIS}

No presente trabalho, pode-se classificar, por todas as características avaliadas e apresentadas, que a planta 6 tem maturação de frutos precoce, sendo melhor aproveitada, se a sua colheita for realizada em meados de janeiro; entretanto, as plantas 2; 3; 4 e 5 apresentaram um ciclo intermediário. Verificouse ainda que a planta 1 foi a mais tardia, necessitando de um período maior para completar seu ciclo.

\section{CONCLUSÕES}

1-A curva de crescimento dos frutos de longan, na região de Jaboticabal, assemelha-se a uma sigmoidal simples.

2-O período ideal para colheita é entre 120 e 130 dais após a antese; após essa fase, o fruto começa a entrar em senescência.

3-A planta 6 apresentou os melhores resultados, podendo ser recomendada como planta-matriz. 


\section{REFERÊNCIAS}

ARAUJO NETO, S.E.; PRAÇA, E.F.; CARVALHO, E.F.; ALVES, R.E. MENEZES, J. B.; MORAIS, E.A.A. Desenvolvimento de frutos de sapotizeiro (Manilka achras (Mill.) Fosberg), Revista Brasileira de Fruticultura, Jaboticabal, v.23, n.1, p. 25-29, 2001.

A. O. A. C. Official methods of analysis of the Association of Official Analytical Chemists International. $16^{\text {th }}$ ed. Washington: Ed. Patrícia Cunniff, 1997. v. 2. cap. 37, métodos 932.12, 942.15. BENZA, J.C. 143 Frutales natives. Lima: Universidade Nacional Agraria La Molina, 1993. p. 366.

CAMPBELL., R.J.; CAMPBELL, C.W. Longan evaluation and selection in Florida, USA. Acta Horticulturae, Wageningen, v. 558, p. $125-27,2001$.

CARNEIRO, J.G. Estudos sobre a caracterização físico-quìmica de frutas: I. Abiu (Lucuna caimito Roem \& Schult.) Revista Brasileira de Fruticultura, Cruz das Almas, v.8, n.2, p. 35-40, 1986a.

CARNEIRO, J.G. Estudos sobre a caracterização físico-quìmica de frutas: II. Jamelão (Syzygium jambolana DC) Revista Brasileira de Fruticultura, Cruz das Almas, v.8, n.2, p. 4143,1986b.

CHITARRA, M.I.F., CHITARRA, A.B. Pós-colheita de frutos e hortaliças: fisiologia e manuseio. Lavras: ESAL/FAEPE, 1990. 320 .

FERRÃO, J.E.M. Fruticultura tropical: espécie com frutos comestíveis. Lisboa: Instituto de Investigação Científica Tropical, 1999. v. 1, p.524.

GALAN-SAUCO, V. Los frutales tropicais en los subtropicos: I Aguacate-Mango- Litchi y Longan. Madrid: Ediciones MundiPrensa, 1990. p. 97-98.

GARCÍA-PEREZ, E; MARTINS, A.B.G. Florescimento e frutificação de lichieiras em função do anelamento de ramos. Revista Brasileira de Fruticultura. Jaboticabal, v.28, n.1, p. 1417, 2006.

GODAS, F.; ALMEIDA, G.B.; BARROS, M. CEAGESP COMPANHIA DE ENTREPOSTOS E ARMAZÉNS GERAIS DE SÃO PAULO. Sistema de informação de mercado. São Paulo: Seção de Economia e Desenvolvimento, 2006. não publicado.
GRIERSON, W. Fruit development, maturation, and ripening. In: PESSARAKLI, M. (Ed.). Handbook of plant and crop physiology. New York: Marcel Dekker, 1995. p.419-35.

HAN, D.M.; WU, X.Z.; Ji, Z.I. Effects of so2 treatment on the overall quality of Longan fruits(cv. Shixia) during cold storage. Acta Horticulturae, Wageningen, v.558, p.375-79, 2001.

LIMA, G.P.P.; KESTRING, D. ; KOHATSU, D.S. ; BOTEON, E.M. Atividade antioxidante de frutos de longan cultivados em Botucatu-SP. In: CONGRESSO BRASILEIRO DE OLERICULTURA, 45., CONGRESSO BRASILEIRO DE FLORICULTURA E PLANTAS ORNAMENTAIS, 15 , CONGRESSO BRASILEIRO DE CULTURA DE TECIDOS DE PLANTAS, 2., 2005, Fortaleza. Anais... p 620.

LIMA, M.A. Conservação pós-colheita de goiaba pelo uso de reguladores de crescimento vegetal, cálcio e da associação destes com refrigeração e embalagens plásticas. 2003. $115 \mathrm{f}$. Dissertação (Mestrado em Agronomia) - Faculdade de Ciências Agrárias e Veterinárias, Universidade Estadual Paulista, Jaboticabal, 2003.

NACIF, S.R. Aspectos anatômicos e fisiológicos do desenvolvimento do fruto de Litchi chinensis Sonn. cv. Brewster (lichia - SAPINDACEAE). 1997. 89f. Tese (Doutorado em Ciências Biológicas)- Universidade Estadual Paulista, Rio Claro1997.

SALOMÃO, L.C.C.; SIQUEIRA, D.L.; PEREIRA, M.E.C. Desenvolvimento do fruto da lichieira (Litchi chinensis Sonn.) 'Bengal'. Revista Brasileria de Fruticultura, Jaboticabal, v.28, n.1, p.11-13, 2006.

SIMÃO, S. Tratado de fruticultura. Piracicaba: FEALQ, 1998. $762 \mathrm{p}$.

STROHECKER, R. L.; HENNING, H. M. Analisis de vitaminas: métodos comprobados. Madrid: Paz montalvo, 1967. 428 p.

WACHOWICZ, C.M.; CARVALHO, R.I.N. (Org) Fisiologia vegetal e pós-colheita. Curitiba: Champagnat, 2002. 424 p.

WAITE, G.K.; HAVANG, J.S. Pest of litchi and longan. In : PENA, J.E. ; SHARP, J.L.; WYZOKI, M. (Ed.). Tropical fruit pests and pollinators, biology, economic importance, natural enemies and control. Wallingford: CAB International, 2002. p.331-359. 